\title{
PARADIGMAS DE CONSERVACIÓN Y MODELOS DE DESARROLLO Y SUSTENTABILIDAD EN VILLA TRAFUL (NEUQUÉN, ARGENTINA)
}

\section{Lara BERSTEN*}

\section{Resumen}

En estas páginas nos proponemos reflexionar sobre los conflictos por la apropiación y el uso de los recursos naturales en la localidad de Villa Traful (Departamento Los Lagos, NeuquénArgentina) situada dentro del Parque Nacional Nahuel Huapi. Describimos y explicamos la creación de dicha localidad como espacio patrimonial y sus transformaciones, vinculada a un modelo específico de naturaleza y preservación, que priorizó el turismo como actividad económica principal en detrimento de otras actividades productivas. Recuperamos la noción de "territorio" como espacio en el que se encarnan las relaciones sociales.

Palabras clave: naturaleza; patrimonio, turismo; desarrollo sustentable; territorio

\begin{abstract}
This paper reflects the conflicts over ownership and use of natural resources in Villa Traful (Department Los Lagos, Neuquén, Argentina) located within the Nahuel Huapi National Park from. By focusing in creation and transformations of the town as a heritage space, from which outlined a specific model of nature was outlined. Such model promoted tourism as main economic activity at the expense of other productive activities. We recover the notion of "territory" as a space in which social relations are embodied.
\end{abstract}

Key Word: nature; heritage; tourism; sustainable development; territory

\section{Résumé}

Dans cette article on se propose réfléchir sur la expérience de la population de Villa Traful (Département de Los Lagos, Neuquén-Argentine) situé dans le Parc National Nahuel Huapi, à partir des conflits pour l'appropriation et l'usage des recours naturels. On décrits la création de cette localité comme espace patrimoniale et ses transformations, et on vincule un modèle spécifique de nature et préservation, qui a priorisé le tourisme comme activité économique principal en détriment d'autres activités productives. Également, nous récupérons ici la notion de "territoire" comme espace où les relations sociales prennent corps.

Mots clé: nature; patrimoine, tourisme; développement durable; territoire

\section{Introducción}

En Villa Traful se vive un proceso de transformación a partir de la implementación de políticas vinculadas al turismo, las cuales recuperan la noción de desarrollo sustentable. El "Plan Federal de Turismo" desarrollado por el Estado nacional, el "Plan de Turismo" elaborado por el

\footnotetext{
* Doctora en Ciencias Antropológicas. Instituto de Ciencias Antropológicas, FFyL-UBA. lara bersten@yahoo.com.ar

Fecha de recepción del artículo:Marzo 2014

Fecha de evaluación: Mayo 2014
} 
gobierno provincial y las propuestas impulsadas desde la Administración de Parques Nacionales buscan situar el desarrollo económico a partir de la valorización y creciente mercantilización de los recursos estéticos característicos del paisaje natural ${ }^{1}$. A partir de esto, desde el municipio de Villa Traful se intenta recuperar estas líneas de gestión para elaborar perfil de desarrollo propio administrado desde lo local.

En nuestra investigación, nos preguntamos respecto de las condiciones de existencia y el contexto histórico del pueblo como espacio patrimonial dentro del Parque Nacional Nahuel Huapi (PNNH en adelante), a partir del cual se estableció un modelo estético específico de naturaleza que direccionó las actividades "permitidas" en dicho espacio territorial. A partir de esto focalizaremos en los cambios en el modelo de preservación señalando las tendencias actuales de desarrollo, influenciadas por los discursos globales sobre la sustentabilidad. Sostenemos que, a lo largo de la historia del pueblo, se produce un pasaje desde un "modelo conservacionista" hacia otro "sustentable" vinculados a la valorización económica del entorno natural. En el transcurso de dicho pasaje, se ponen en relieve los conflictos locales que históricamente configuran las relaciones de vecindad en el pueblo.

Traful fue creada como una villa turística dentro del PNNH con el objetivo de consolidarse como un centro turístico de "elite", su localización, la dificultad de acceso al lugar y la falta de infraestructura, condicionaron la concreción de dicho proyecto. Villa Traful adquirió un perfil turístico estacional, por lo que las hosterías y cabañas hasta hace muy poco tiempo sólo permanecían abiertas durante los tres meses que dura la temporada estival generando que la vida social y de trabajo del pueblo se polarice entre invierno y verano ${ }^{2}$. La infraestructura limitada, también hizo que aquellos turistas que les interesa el confort como base principal para su descanso, buscaran instalaciones con mayores comodidades en Bariloche y Villa La Angostura, y ocasionalmente visitaran Traful durante el día. Por lo tanto el principal afluente poblacional que llega a la zona, ha sido aquel que busca experiencias diferentes ligadas al turismo agreste, vinculado generalmente principalmente a la pesca deportiva y en menor medida a la caza. Si bien esto era considerado como una debilidad, en el presente también es su fortaleza, sobre todo para aquellos visitantes que buscan experiencias turísticas más silvestres y alejadas de zonas urbanas.

En la actualidad, Villa Traful es un pueblo de 503 habitantes, entre los cuales podemos señalar grupos definidos a partir de los períodos históricos que accedieron al pueblo, pero que también se diferencian a partir de la situación dominial de la tierra y el acceso a la vivienda. El primero y más numeroso lo constituyen las familias de tradición campesina, que se han dedicado a la cría estacional de ganado con campos de invernada y veranada. Actualmente esta actividad se realiza de modo marginal y mayoritariamente realizan trabajos estacionales de baja calificación para el turismo o como empleados públicos en la comuna. Este grupo se auto denomina y es reconocido como tal por el resto de la población como pertenecientes a las "familias de primeros pobladores", ninguno de ellos es propietario de las tierras que ocupan. Si bien muchos de estos pobladores se reconocen como descendientes del pueblo Mapuche, en el presente no existen reclamos organizados en relación a reivindicaciones étnicas. Un segundo grupo, minoritario pero con mayor visibilidad pública está compuesto por distintas camadas de inmigrantes que desde la década del ' 40 a la actualidad se instalaron en la localidad y que se dedicaron a actividades vinculadas al turismo, quienes han logrado la titularidad de las tierras. Un tercer grupo bien reducido que son los migrantes más recientes.

Esta localidad erigida en las costas del río Traful y al pie de la Cordillera de los Andes, desde su conformación, ha sido categorizada por el Estado Nacional como un espacio de valor

\footnotetext{
${ }^{1}$ Por razones de espacio no profundizaremos en estas propuestas de gestión.

2 Cuando comenzamos el trabajo de campo, en 2007, se estaban realizando los trabajos de asfaltado de la ruta nacional No 234 que conecta a Villa La Angostura con San Martín de los Andes. Si bien la vía de acceso al pueblo (tanto desde la ruta nacional $\mathrm{N}^{\circ} 40$ que comunica con Bariloche, como desde la ruta $\mathrm{N}^{\mathrm{o}} 234$ por la que se accede a Villa La Angostura y San Martín de los Andes) continúa siendo de ripio, el asfaltado de esta ha facilitado la conexión con Villa La Angostura (ciudad vecina de jurisdicción neuquina, a diferencia de Bariloche).
} 
excepcional por sus recursos naturales, integrando uno de los principales recorridos turísticos del país. Aquí nos interesa analizar el proceso a través del cual se constituyó como "patrimonio natural" y cuáles fueron las políticas de conservación que delinearon la geografía actual. En este trabajo abordaremos dos momentos contrastantes con relación a la preservación medioambiental. Por un lado el ideario inicial con relación a los Parques Nacionales, - modelo o paradigma de larga duración- que sitúa al paisaje como "espacio de conservación". Por el otro, las modificaciones graduales a partir de las cuáles el PNNH enmarca sus políticas dentro de propuestas de "desarrollo sustentable".

Para llevar adelante el trabajo hemos utilizado la metodología cualitativa propia de la Antropología Social, basada en la observación participante, y entrevistas abiertas y semiestructuradas, -con trabajo de campo realizado entre 2007 y 2010-, junto con el análisis de fuentes de información secundaria como documentos de organismos oficiales y censos.

\section{Discusiones sobre el desarrollo y tendencias actuales}

Las discusiones en torno al "desarrollo", como categoría conceptual, se inician en el período de posguerra y recorre el siglo XX hasta nuestros días. Hasta principios de la década de los ochenta, en Latinoamérica dominaron los enfoques regionalistas en el campo del análisis espacial (Manzanal 2005a). Estos enfoques se basaban en la definición de grandes unidades espaciales en base a su relativa homogeneidad, empleando principalmente variables macroeconómicas y socio-demográficas. Uno de los rasgos característicos de toda esa maquinaria de conocimiento y poder, consiste en la abstracción de los problemas de su marco político y cultural, formulándolos como problemas técnicos a lo que se les propondría soluciones neutrales (Wood 1985). Hasta los '80, lo rural y específicamente lo agropecuario, eran entendidos mayoritariamente como uno de los principales factores explicativos del "atraso" en las sociedades latinoamericanas, en base a una lógica de oposiciones dicotómicas entre dos polos (centro/periferia, tradicional/urbano, o moderno/atrasado). A partir de estas dicotomías se definía la dinámica de las relaciones económicas y sociales al interior de estas naciones (Benedetti y Carenzo 2006).

No obstante, tras la crisis económica de los años '70, los movimientos políticos en los países periféricos, la re-definición de los Estados-Nación y la participación de los organismos internacionales, la categoría de "desarrollo" se vió sometida a un amplio debate. El liderazgo de la Organización de las Naciones Unidas (ONU) y los organismos internacionales de crédito, vinculadas a los centros del poder hegemónico, esbozaron alternativas a las nociones tradicionales de desarrollo. A fines de los '70, estos organismos comenzaron a fijar rumbos políticos para los países considerados del "Tercer Mundo" a partir de lo que dieron en llamar "desarrollo endógeno". Esta concepción ganó mucha aceptación, dado que rechazaba la necesidad o la posibilidad de la imitación mecánica con las sociedades industriales y sostenía que era necesario buscar las especificidades locales como vía al desarrollo (Esteva 2000). En el año 1987, en el marco de estas discusiones, la ONU elaboró un informe socioeconómico Nuestro Futuro Común- conocido como el informe Brundtland, en el que se utilizó por primera vez el término "desarrollo sostenible", definido como "aquel que satisface las necesidades del presente sin comprometer las de las futuras generaciones". Este concepto ganó enorme aceptación dando lugar a distintos intentos de lograr nuevos balances entre la calidad del ambiente y las actividades humanas (Gudynas 2010: 43), tornándose un tema ineludible y un eslogan de gran difusión. Las propuestas de desarrollo (endógeno, local, territorial rural, sostenible) adquirieron fuerza en Latinoamérica durante los '90, de la mano del neoliberalismo y los procesos de descentralización (Manzanal 2007). Aquí, me interesa retomar la noción de "desarrollo sustentable", formulada en un contexto de crisis medioambiental y sobreexplotación de los recursos naturales, que evidenciaron que las metas de conservación de la naturaleza exigían repensar las estrategias de desarrollo. Por lo tanto comenzaron a discutirse modelos que intentaran revertir esta situación y se manifestó la necesidad de tránsito hacia un estilo de 
desarrollo sustentable (Guimaraes 1994). No obstante, según Reboratti (1996) esta noción se utiliza como si implicara una aquiescencia general, con validez universal y atemporal. Si bien el "desarrollo sostenible" ha ganado gran aceptación no es una definición consensuada y continúa siendo ambigua, confluyendo en posturas muy diferentes con definiciones vagas (Gudynas 2010, Reboratti 1996).

Escobar (1996) efectúa una crítica a estas concepciones de "desarrollo endógeno", proponiendo la desnaturalización del mismo (y su neutralidad), haciendo hincapié en la "creación" de un discurso, que no puede escindirse de la noción de "tercer mundo" y "subdesarrollo", considerada una nueva forma colonialista de intervención en los países periféricos. Este autor propone recuperar las propuestas resultantes de una elaboración colectiva (grupos políticos organizados), surgida en los territorios como instancia superadora denominada postdesarrollo (Escobar 2005).

La noción de desarrollo no sólo es cuestionada desde el ámbito académico, sino también desde lo político. No obstante esta categoría se encuentra fuertemente enraizada en el ámbito público señalando su persistencia aunque se vaya modificando su contenido. Como plantea Mannheim las mutaciones sociales no tienen nunca el carácter de una construcción radicalmente nueva, sino que lo nuevo y lo viejo se reúnen en un proceso de transformación (1984). Por tanto, más allá de las críticas no podemos desconocer que las políticas hegemónicas de desarrollo sustentable (vinculadas al surgimiento del ambientalismo, en el seno del neoliberalismo) han logrado difundirse como premisa básica y trasversal a las políticas públicas, aunque con una importante variabilidad respecto de su aplicación concreta. La categoría mencionada tienen un profundo impacto en la vida social (e institucional) pero con características polisémicas, muchas veces no explicitadas, abarcando así acciones diversas bajo las mismas premisas.

Por lo tanto en este trabajo no desconocemos los discursos globales con relación al desarrollo y a la sustentabilidad, que por su difusión global impactan en los territorios, pero analizaremos dichas propuestas, formulaciones y reformulaciones desde lo local en su interrelación con las políticas de Estado. Consideramos que para que las premisas de "desarrollo sustentable", adquiera sentido, debe estar situada, dado que las medidas que se toman apelando a dicha concepción, tiene implicancias territoriales. Consideramos fundamental identificar de qué manera se piensan y se formulan políticas de desarrollo enraizadas en el territorio y analizar cómo se construye cierto ideario de "la naturaleza" en el proceso social, de qué manera la cultura posiciona a la naturaleza, cosificada, en un campo de disputa de poder.

\section{La impronta regional establecida por el Parque Nacional Nahuel Huapi}

A principios del siglo XX Francisco Pascasio Moreno donó a la nación 7.500 ha., ubicadas en la región del Nahuel Huapi para constituir un parque natural ${ }^{3}$. La condición era que las mismas se reservaran como zona intangible -sin ocupación humana- para convertirlo en un parque nacional en tanto espectáculo de la humanidad y fuente de la representación patriótica, sentando las bases para la creación de las áreas protegidas (Carpinetti 2005). En esta concepción la naturaleza aparece escindida del mundo social, separación característica del proyecto de modernidad Occidental. Como sostiene Glacken (1996), la gran ruptura que surge con el pensamiento moderno es que se va a desdibujando la idea de totalidad y se va consolidando la idea de dos entidades escindidas (hombre/naturaleza). Esta visión concluye con la objetificación de la naturaleza, a partir de la cual la misma pasará a ser vista como recurso, un ámbito por fuera de la cultura a la que es posible recurrir para satisfacer las necesidades del hombre (Mastrangelo 2009).

\footnotetext{
${ }^{3}$ Esta donación formaba parte de los territorios que previamente había recibido por parte del Estado en pago por su rol en el peritaje brindado al Estado en el conflicto limítrofe con Chile.
} 
En 1934 se crea la Administración de Parques Nacionales (APN, en adelante) por medio de la Ley promulgó la Ley $\mathrm{N}^{\mathrm{o}} 12.103^{4}$, conformando también Parque Nacional Nahuel Huapi, como la primer área de reserva de la institución. Exequiel Bustillo primer presidente de la APN-cargo en el que permaneció durante 10 años-, estableció el régimen de funcionamiento de las áreas protegidas. La APN se constituyó en el referente del Estado nación en la región, institución que, como veremos, tuvo un rol preponderante en la configuración económica, política y social del territorio.

Se instauró una imagen simbólica europeizante en el PNNH, concordante con el ideal estético y social que la clase dominante deseaba para el lugar. A esto ha contribuido cierto parecido físico con Los Alpes, imaginario ligado a la clase dominante, deseosa de forjar en la región de Los Lagos la "Suiza argentina" (Navarro Floria 2008). La región del Nahuel Huapi fue categorizada como un espacio a ser preservado, a partir de la valorización estética del paisaje, acorde al modelo hegemónico de identidad nacional. En este sentido, la "preservación de la naturaleza" se constituyó en un argumento que facultó al Estado para ejercer un control geopolítico del territorio. Pero, al mismo tiempo, se imbricó con prácticas que fueron afianzando una identidad nacional en el territorio excluyente y acorde a un ideario político hegemónico asociado a grupos de élite. Estas prácticas no sólo implicaron el establecimiento de una arquitectura "europea" sino también la introducción de flora y fauna extranjera en detrimento de las especies nativas así como políticas sociales de control de la población. Desde épocas tempranas las políticas de desarrollo impulsadas por el Estado tendieron a crear las infraestructura necesaria para posicionar esta zona como destino turístico exclusivo, a partir de un ambicioso plan que abarcaba la construcción de hoteles, caminos, puentes, senderos, edificios públicos, etc.

Parques nacionales ha ejercido, desde entonces hasta nuestros días, un rol clave en el desarrollo regional de la zona del lago Nahuel Huapi, fomentando el turismo en detrimento de las actividades agrícola-ganaderas y forestales características de la zona hasta ese momento (García et. al. 2008). La APN actuó en este primer período como un poder autárquico real y efectivo en los Territorios Nacionales. Esta institución se encargó del loteo de tierras, autorizaciones para la instalación de pobladores, fijó los cotos de caza y realizó el control de la tala de árboles. A los pobladores locales, se les exigía un estricto cumplimiento de las normas vigentes, más aún si eran chilenos e indígenas (Méndez 2009). Se profundizaron políticas de no reconocimiento de los pobladores, llegando en muchos casos al enfrentamiento, la expulsión forzada o la permanencia del grupo familiar sólo mientras viviera el titular del Permiso Precario de Ocupación y Pastaje (en adelante PPOP) (Bersten 2009, Méndez Op. Cit) ${ }^{5}$. En contraposición se favoreció a sectores de elite, por medio de la entrega de amplias extensiones de tierras, que consolidaron una naciente clase dominante local, los "pioneros" (De Mendieta 2002) ${ }^{6}$.

A través de estas políticas, parques nacionales buscó entrelazar procesos de construcción de identidad nacional, asentados en un ideario civilizatorio representado en un origen europeo, el territorio y la naturaleza. La categoría de "pionero" fue funcional a esta operatoria, dado que representaba al sujeto civilizado que iba a "colonizar" el territorio, diferenciándose de los habitantes preexistentes: los indígenas. Si bien en este período inicial la preservación medioambiental no adquirió centralidad, constituyó el argumento principal de control hacia los pobladores indígenas y chilenos asentados en el territorio (previa consolidación del parque). El argumento de la protección de la naturaleza, en pos del beneficio de la nación fue adquiriendo un matiz nacionalista, dado que los abusos eran cometidos por "chilenos", vanguardistas de un expansionismo territorial del país vecino (Scarzanella 2002: 9).

\footnotetext{
${ }^{4}$ La denominación institucional de la actual Administración de Parques Nacionales, fue cambiando en diversas ocasiones, para unificar criterios y no confundir al lector, nos referiremos bajo la sigla APN.

${ }^{5}$ Como consecuencia de estas políticas se documenta una sensible reducción de la cantidad de población asentada dentro del Parque en los años transcurridos entre los censos realizados por la misma institución en 1934 y 1965, evidenciando la política de expulsión de la población (indígenas mayoritarios y algunos inmigrantes) (Pérez 2009).

${ }^{6}$ Estas políticas muestran una línea de continuidad con la "campaña al desierto" que tenían por objeto "llevar el progreso" a la Patagonia, asociado con los valores y modos de vida de Occidente.
} 


\section{Papeles de Trabajo No 27 - Julio 2014 - ISSN 1852-4508 \\ Centro de Estudios Interdisciplinarios en Etnolingüística y Antropología Socio-Cultural}

Las políticas del PNNH en su fase inicial y de larga duración se centraron en la preservación medioambiental como un modo de control geopolítico, pero también de restringir y expulsar a la población allí presente, fomentando dicho espacio como un lugar de descanso de las elites, es por esto que en 1934 se fundan 7 villas turísticas entre ellas Villa Traful ${ }^{7}$. La política de la APN persistió, a grandes rasgos, hasta el fin de la última dictadura militar'. Hacia los '80 con el regreso a la democracia y el impacto de los discursos neoliberales estas políticas comienzan a modificarse y a partir de los últimos años el desarrollo sostenible se entrelaza con la conflictividad social y las demandas territoriales lo que ha conducido a nuevas formas de comanejo dentro del Parque Nacional ${ }^{9}$. Observamos, que al abarcar el PNNH territorios provinciales diferentes (Neuquén y Río Negro), implica especificidades acorde a la vinculación con cada una de ellas. Por otra parte, el citado proceso regional, adquiere especificidades en la localidad Traful, lo que nos permite observar de qué manera los términos generales de las políticas se encarnan localmente.

\section{Villa Traful en el contexto del Parque Nacional Nahuel Huapi}

Las tierras "conquistadas" (post Campaña al Desierto) pasaron a formar parte del patrimonio fiscal del Estado, dentro de la circunscripción del Territorio Nacional de Neuquén ${ }^{10}$. Al mismo tiempo que se crearon las herramientas institucionales para la consolidación de este espacio como territorio de gobernanza, se inició el proceso de privatización de la tierra. En Traful la consolidación del espacio de gobernanza y de la propiedad privada fue en paralelo y sólo pueden comprenderse en su imbricación o su creación conjunta. La propiedad privada de la

\footnotetext{
${ }^{7}$ Los desalojos se frenaron durante el peronismo, período en el cual, por otra parte, se fomentó y diversificó el turismo, lo que permitió por medio de acuerdos y convenios el acceso al PNNH de un "turismo popular", sobre todo en la zona de Bariloche (Nuñez y Vejsbjerg 2010). Inclusive en este período se decretaron expropiaciones a las grandes estancias (registradas en documentos de la APN), que no lograron concretarse como consecuencia del golpe que derribara a Perón en el año 1955.

${ }^{8}$ No queremos decir que la política de esta institución haya sido homogénea, de hecho durante el peronismo se impulsaron importantes cambios. No obstante las constantes rupturas democráticas inhibieron la formulación de proyectos políticos de largo plazo y a su vez favorecieron las políticas de corte autoritario durante los períodos de facto.

9 En el año 2000 el Parque Nacional Lanin implemento el co-manejo entre comunidades mapuche y el Parque. Durante varios años se trató de trasladar esta figura al PNNH siguiendo el modelo precursor, pero dadas las características específicas, no se pudo replicar de igual manera. La diferencia fundamental entre ambos parques, desde la creación del Lanin se reconoció a las comunidades mapuche, asignándoles territorios específicos. Esto hizo que al momento de crear el de co-manejo, se planteara como una instancia de co-gobierno y negociación entre la Intendencia del parque y la población indígena. Mientras que en el PNNH -hasta hace unos pocos años- no había reconocimiento de comunidades, aunque si se encontraba presente la figura de "poblador". En los últimos años de la mano de los procesos de reorganización indígena o etnogénesis, han aumentado las demandas al parque, tanto por el reconocimiento en procesos de recuperación territorial, como por el co-gobierno. Como consecuencia de esto a fines del 2007 se implementó el "Programa de Pobladores y Comunidades de Pueblos Originarios", contemplando las particularidades del Nahuel Huapi, con variables diferencias acorde a la capacidad de organización y demanda de las comunidades mapuche y pobladores del Parque. No obstante los trafulenses no participan de esta experiencia. Esto se debe a qué, cómo se mencionó, las 620 hec. del ejido municipal fueron provincializadas por ende el alcance de dicho programa no tienen alcance sobre Villa Traful.

10 Para analizar el proceso de consolidación del Estado en la zona, retomamos el aporte de Fernandes (2010) deudor de Lefevbre, quien considera al territorio como construcción social implica que éste no es algo dado, sino que abarca una multiplicidad de fenómenos articulados de índole económica, política e ideológica que pueden entrar en contradicción. Para abarcar esta complejidad Fernandes (Op. Cit.) propone una tipología de territorios con miras a integrar los intereses puestos en juego, las acciones, relaciones y conflictos, superando así la visión simplista que plantea al territorio como espacio de gobierno. La tipología mencionada propone en primer lugar, la separación analítica entre territorios materiales e inmateriales. Lo que nos interesa retomar para el análisis es la diferenciación esbozada por el autor con relación al primero, al que subdivide en tres: a) espacios de gobernanza (Estados, provincias, municipio, etc.); b) la propiedad (contemplando diferentes tipos de propiedad), y c) las territorialidades que comprende las formas tradicionales de habitar el espacio, las formas de uso de los actores locales. Si bien esta diferenciación permite ver las especificidades de cada uno, se señala que éstos sólo existen en su interrelación (Fernandes 2010: 16).
} 
zona, se materializó a partir de "los alambrados", que delimitaron un adentro y un afuera, es común escuchar la frase "los empezaron a correr los alambrados". Muchos de estos pobladores de origen humilde se vieron presos de este reparto de tierras ya que habitaban lugares que quedaron ubicados dentro de las propiedades privadas, por lo que comenzaron a hacer acuerdos como medieros como condición para permanecer allí. En aquel entonces comenzó a materializarse la concepción de una frontera entre lo público y lo privado, de propiedad y de derecho; siendo el Estado el garante de los mismos, a partir de lo cual superpuso y subvirtió otros tipos de habitar el territorio y modificó la vida cotidiana de los pobladores rurales allí asentados.

La Dirección de Tierras y Colonias reconoció la ocupación real y efectiva de los lotes previamente ocupados que no quedaron comprendidos dentro de las estancias, a través de los PPOP, permisos precarios de ocupación que no reconocían la propiedad de la tierra sino sólo su usufructo. Estos permisos debían pagarse todos los años pero, según los recuerdos e historias familiares, sus ocupantes podían ser desalojados en cualquier momento.

"En el '36 llegó Parques con permisos precarios para los pobladores, los pobladores fueron los que les firmaron esas cosas. Realmente no sabían nada cómo defenderse de la ley mis padres. Los últimos años realmente los engañaron." (Pobladora de Villa Traful)

Con la creación del PNNH, los permisos emitidos por Tierras y Colonias fueron transferidos a esta institución. Los PPOP asignados originalmente por la Dirección de Tierras y Colonias que quedaron bajo la jurisdicción del PNNH, se reestructuraron acorde a los objetivos de esta institución generando situaciones conflictivas en torno a la propiedad, trasladando a los pobladores o incluso desalojándolos. Desde los primeros años del PNNH, los pobladores debieron acostumbrarse a la provisoriedad e inseguridad frente a la amenaza de desalojo y debieron aprender a negociar o demandar frente a normativas, leyes y restricciones impuestas. En algunos casos, sus espacios de residencia fueron loteados y vendidos, las "antiguas divisiones de los abuelos" quedaron olvidadas y muchas familias fueron "corridas" de las tierras que ocupaban para dejar lugar a la construcción del centro urbano de la nueva villa turística, relocalizando a las familias e interrumpiendo sus pautas y modos de vida.

Por otra parte, los permisos de residencia y los pastajes eran por familias, pero como la tierra era de dominio público del Estado nacional impidió el posterior fraccionamiento por parte de los grupos familiares extendidos, imposibilitando el reconocimiento, por vía jurídica, de divisiones al interior de los grupos domésticos. Esto generó continuos conflictos y peleas entre los hermanos, ya que cuando los hijos crecían y el titular del PPOP fallecía, sólo uno de ellos podía resultar titular del permiso.

Las normas de ocupación fueron sumamente estrictas con el modo de vida y actividades desarrolladas por ellos, "las mejoras" que podían realizar, la cantidad de animales que podían criar, la cantidad de leña que debían tomar del bosque ${ }^{11}$. "No se podía arreglar la casa; la limitaban. Para todo una infracción, una multa" (Pobladora de Villa Traful). El PNNH estipuló cotos de caza y pesca, de tenencia de ganado, de tala de árboles y prohibió la práctica de rozados, limitando el libre acceso de las familias las tierras donde realizaban estas actividades. En este contexto, la ganadería (como consecuencia de la restricción a la cantidad de animales) y la huertas de autoconsumo fueron perdiendo influencia en la economía familiar.

"Cuando tenía más o menos 10 años había leche, huevos, pollo, porque acá mi abuelito tenía de todo. Tenía caballos, vacas, ovejas, chivos, chanchos, gansos, pavos. Después parques prohibía los chivos y chanchos, no se podían criar más. Sólo teníamos vacas, caballos y ovejas. De un día para otro tomaron todo" (Pobladora de Traful)

Otro de los inconvenientes que se presentaba era la dificultad que representaba para los pobladores el pago de los impuestos que había establecido el PNNH

"yo me acuerdo que era muy dificil reunir el dinero. Porque vos imagínate que antes había mucho

\footnotetext{
${ }^{11}$ Si bien la "llegada de parques" para los pobladores marca un antes y un después, es necesario enfatizar que desde hacía ya varios años venían implementándose en el territorio políticas estatales. Un claro ejemplo de esto es el rol ocupado por la escuela, que evidencia la presencia institucional aunque la diferencia reside en que ésta no necesariamente es señalada de manera negativa por los pobladores.
} 
menos gente, menos movimiento, los turistas no entraban casi. Así que vender un animal era muy difícil... y vendiendo sólo uno tampoco podías pagar el pastaje [impuesto]" (Poblador de Villa Traful)

La necesidad de adquirir dinero para el pago de impuesto introdujo el asalariamiento en las estancias de la zona (propiedad de los "pioneros") (Pérez 2009). Este proceso contribuyó a que se produjeran migraciones y rupturas de los grupos familiares extensos, logrando así el PNNH controlar el crecimiento poblacional del territorio y desplazar a parte de población allí presente. Es decir que las políticas basadas en la administración de los recursos naturales implicaron también un control y redistribución de la población. Frente a estas nuevas normativas y controles, aparece como vector de los relatos de los "primeros pobladores" la noción de “desprotección” en los primeros años del PNNH. Sostienen que no sabían cómo manejarse ante las formas burocrático-administrativas del Estado, a las que se sumaban prácticas coactivas de los funcionarios del PNNH que los obligaban a "firmar papeles", desconociendo realmente de qué se trataba.

Asimismo el parque fijó un riguroso diseño de construcción, que implicó un cambio radical en la estética de la región (disposiciones se extendieron a todas las villas turísticas). Se condicionó las ventas de las tierras a la realización de costosas mejoras, estableciendo estrictas normas edilicias que la mayoría de los pobladores no estaba en condiciones de afrontar. Para fines de los años 30 se procedió a la venta de lotes en Traful, con poco éxito y quienes adquirieron los loteos fueron gente adinerada que, en su mayoría, no establecieron residencia permanente en el lugar. El poco éxito en la venta de terrenos se debió a la ubicación de la localidad, la dificultad en el acceso, la poca infraestructura y la débil consolidación institucional.

La construcción territorial de Traful se caracterizó por la consolidación de un reducido grupo de propietarios mientras que el resto de los ocupantes no logró la titularización, estableciendo relaciones de poder asimétricas entre ambos. Podemos observar que en los discursos presentes en Norpatagonia, así como en los relatos específicos de Traful, estos primeros propietarios, "extranjeros", asentados en la zona a fines del siglo XIX han sido denominados como "pioneros", mientras que los ocupantes sin título que se asentaron en la zona en el mismo período histórico, son referenciados como "pobladores" o "primeros pobladores". La creación de la localidad de Traful dentro del área protegida, en tanto patrimonio natural del Estado, se consolidó a partir del establecimiento de relaciones de poder específicas, que afianzaron dos grupos definidos los propietarios y los no propietarios, en tanto grupos subalternos.

En palabras de los "primeros pobladores" de Traful, la "llegada de parques", -tal como hacen referencia para relatar el proceso de consolidación institucional del PNNH-, implicó un quiebre en su vida cotidiana. Las políticas del PNNH vinculadas a la concepción de "reserva natural", entendido como un espacio separado o aislado y el discurso de defensa medioambiental, encubrieron las prácticas represivas por medio de las cuales el Estado negó, corrió y expulsó a los habitantes indeseables de estas tierras.

El PNNH se estableció como un enclave nacional, con un perfil elitista acompañado de un modelo de preservación que operó como un modo de segregación, expulsión y apropiación respecto de los "primeros pobladores". Estas memorias en Traful hasta el momento no se cristalizan en un pedido de reparación (en términos generales), sino que tienen un sentido proyectivo y de apropiación de los beneficios económicos que puede brindar el plusvalor que les otorga estar dentro de un parque nacional consolidado y de gran prestigio a nivel nacional e internacional.

En este sentido en vinculación con las políticas nacionales y provinciales volcadas hacia las premisas de desarrollo sustentable, se comienzan a formular propuestas de turísticas, gestionadas y administradas desde lo local. No obstante esto no implica al interior de Traful una homogeneidad de intereses respecto del aprovechamiento y administración del mismo. 


\section{Administración local, propuestas de desarrollo y condiciones laborales}

Como señalamos el PNNH creó y administró dicho territorio, pese a que la localidad se encuentra dentro de la circunscripción neuquina. Esto trajo aparejado numerosas disputas entre el gobierno nacional y el gobierno provincial. En 1969, por medio del Decreto Provincial Nro. 0769 se conformó la Comisión de Fomento de Villa Traful como órgano de gobierno local. Pese a la institucionalidad provincial, el municipio se conformó como una "isla" municipal dependiente de ámbitos de decisión provinciales quedando envuelta en un espacio de gobernanza territorial nacional. Esto conllevó numerosos reclamos por parte de la provincia y diversas disputas por el manejo del territorio. Recién en el año 1994 la nación le traspasó al municipio un radio de 620 hectáreas que comprende el casco urbano del pueblo.

A partir de esto del traspaso de tierras cambiaron los modos de adjudicación de la tierra, los pobladores (con PPOP) vieron reducidas sus ocupaciones a un máximo de 2 hec. con la promesa de titularización de la tierra (aún no sucedió). Paralelamente se promovió la creación de un barrio, en el que residen los "nacidos y criados" (nyc), descendientes de los "primeros pobladores" del pueblo en búsqueda de trabajo). Tal como cuenta Estanislao, “...en mi juventud tuve que emigrar a Bariloche, por razones de que poco trabajo, no podia seguir estudiando porque mi padre era empleado y no había manera de comprar las cosas y empecé a trabajar". El gobierno provincial prometió la titularización de los territorios y las casas aunque hasta el presente esto no sucedió.

Actualmente el mercado de tierras se mantiene cerrado por ende el crecimiento habitacional y poblacional es bajo, representando un inconveniente, por ejemplo, para los funcionarios que van a vivir al pueblo, tal como nos contara el médico local que le sucedió a la enfermera del puesto de salud. "Como no consiguió casa, la enfermera vino a vivir acá al lado, en una piecita con un bañito, compartiendo paredes de por medio conmigo, escuchamos lo que hablamos, lo que decimos, todo". Esta situación, hace que casi no haya migraciones de carácter permanente en la localidad ${ }^{13}$. En los casos que alguien llega al pueblo y entabla algún vínculo sentimental con algún lugareño es común escuchar, "la pegó porque sale con X que tiene un terreno". Como ya se planteó, en el pueblo hay una marcada distinción entre los propietarios y no propietarios, pero a este segundo grupo podríamos ampliarlo diferenciando entre aquellos que dada su pertenencia a las familias de "primeros pobladores" tienen PPOP (ya sea de parques o de provincia) o quienes por parentesco con éstos han obtenido viviendas, bajo formas accesibles de pago.

La dinámica de la vida local ha estado estructurada por una definición preservacionista del espacio y la actividad económica principal es el turismo estacional, influenciando las trayectorias laborales. Los propietarios de las hosterías y cabañas, mantienen sus puertas abiertas sólo durante el verano, con excepción de unas cabañas que hace cuatro años sostienen sus servicios durante todo el año. Existe sólo un empresa turística dedicada a brindar servicios de paseos en el lago, "Ecotraful" (aunque su dueño no es oriundo de Traful), hay comercios de gastronomía (restaurante, rotisería, proveeduría), pero el resto de los habitantes que trabaja con relación al turismo lo hacen vendiendo su fuerza de trabajo, generalmente como mano de obra barata y no calificada (servicio de limpieza, mozos, lavanderas). Otros ofrecen caminatas, cabalgatas o venta directa de productos al turismo como pan, dulces, etc. Generalmente todas estas formas de trabajo son informales o no registradas.

\footnotetext{
12 Las categorías de "nacidos y criados" es de amplia difusión y utilización en la Patagonia, al igual que la de "primeros pobladores". Esta última además refiere a la denominación que se le dio desde épocas tempranas a los pobladores de la zona, invisibilizando así la pertenencia étnica. Esto fue abordado en mi tesis doctoral "Construyendo naturalezas Patrimonio natural y administración sustentable en Villa Traful (Neuquén, Argentina)", la cual se encuentra en su fase final de redacción.

${ }^{13}$ Lo más común con relación a las personas que se asientan en Traful, es que primero lleguen a la localidad a desarrollar alguna tarea o función y luego deciden quedarse. Es este conocimiento previo del lugar lo que les permite ir viabilizando la posibilidad de acceso a la vivienda.
} 
También existe un circuito de personal estacional, que llega al pueblo durante el verano a ocupar cargos en hosterías o cabañas y que generalmente tienen una formación específica vinculada al turismo y se retiran al finalizar la temporada. Durante el verano parte de los pobladores, tienen tres o cuatro trabajos, mientras que durante el invierno la oferta es casi inexistente. Por lo tanto quienes venden su fuerza de trabajo deben organizarse, "estirar" el dinero para el resto del año, por lo que es común escuchar en la localidad la frase "los pobladores de Traful sobrevivimos del turismo". Como consecuencia de esta marcada estacionalidad en la oferta laboral, sobre todo para quienes no tienen trabajo en blanco o contratos que se extiendan durante todo el año, la ayuda social constituye una fuente fundamental de ingreso. Asimismo el trabajo público constituye una meta a alcanzar, como consecuencia de la estabilidad que otorga.

Si bien en la actualidad la ganadería representa un aporte marginal, para algunos pobladores, sobre todo para aquellos que realizaron tareas en el campo durante toda la vida, es una actividad significativa en el desarrollo de sus vidas y además complementaria sobre todo para las épocas de escasez de trabajo. En este sentido el mantenimiento de actividades rurales, también posibilita la obtención y generación de alimentos a través de sus conocimientos y por sus propios medios.

Otra de las cuestiones que adquiere relevancia en la cotidianeidad del pueblo es el "asistencialismo" o "ayuda pública". Es común escuchar, la visión negativa al respecto, sobre todo de funcionarios no involucrados en el reparto de bienes asistenciales. Consideran a estas políticas un freno para el desarrollo porque alegan que inhiben la voluntad de los pobladores de mejorar por sus propios medios ${ }^{14}$, "En Traful hay mucha dependencia del Estado, no vas a encontrar miseria (...) Pero lo malo de esto es que no hay incentivo, entonces hay toda una situación de conformismo, que a la larga es mala." (Horacio, poblador de Villa Traful y ex funcionario de la Comisión de Fomento). La relevancia de la ayuda pública en la provincia, es necesario comprenderlas en el marco del Estado benefactor neuquino y los cuantiosos ingresos producto de la coparticipación de las regalías energéticas. (Favaro 1994). Además de la fuerte impronta de la ayuda pública, también existe una gran cantidad de trabajo público en la localidad. Si bien claramente el trabajo público y la ayuda social, no son lo mismo, los discursos esgrimidos en el caso de Traful parecieran confundir u homologar una cosa con la otra.

A partir de estas imágenes de Traful, nos interesa puntualizar cuestiones de diferentes órdenes. Primero plantear, las dificultades que conlleva para los pobladores "vivir en un espacio patrimonial", el cual direcciona a los habitantes a trabajar en el turismo, inhibiendo otras actividades productivas. Por otra parte también observamos una polarización entre quienes son propietarios y dueños de emprendimientos turísticos como hosterías, cabañas o restaurantes, -los que obtienen los importantes ingresos provenientes del turismo- y los pobladores a quienes obtienen una remuneración en "negro", que no alcanza para asumir el costo de vida durante el resto del año.

Por lo tanto la exclusividad de vivir en un espacio patrimonial representa un beneficio para los propietarios de hosterías, cabañas y restaurantes que además, debido a las pocas plazas que hay en el pueblo y la importante demanda tienen un costo alto con relación a otros lugares de la zona. Mientras que para resto de los pobladores, quienes además no tienen capital para invertir en emprendimientos turísticos, son quienes "sobreviven del turismo". Al mismo que muchos habitantes plantean la dependencia de los pobladores de la ayuda social, o la falta de progreso o cambio en los modos de vida (reforzando también el rol en la degradación del medioambiente de estos pobladores), es esta situación la que habilita a que las hosterías y cabañas puedan contar con mano de obra barata estacional, no registrada y disponible siempre que abren sus puertas.

\footnotetext{
${ }^{14}$ Entre la ayuda social que reciben en el pueblo podemos mencionar el Plan calor (provee leña del aserradero comunal para calefaccionar el hogar en el invierno pero también arreglar la casa), cajas de comida desde nación y provincia, el Plan Materno Infantil, y actualmente la Asignación Universal por Hijo.
} 
Frente a esta situación, el Municipio viene sosteniendo la necesidad de lograr un desarrollo administrado localmente, viabilizado por medio de la expansión turística, que permita mejorar las condiciones del pueblo de manera sustentable. Las propuestas de la Comuna con una fuerte vinculación con la Cámara de Comercio se centraron en sentar las bases para desarrollar el turismo, consolidado de manera estable durante todo el año. En su discurso de asunción el primer presidente electo de la Comisión de Fomento sostuvo,

"Desarrollemos el turismo, a escala humana, sin sacrificar la naturaleza. Nuestra Villa puede ser un destino turístico diferente en la Zona de los Lagos. Tenemos nuestra propia personalidad como Aldea (...) [Los turistas] por sobre todas las cosas vienen a conocer y a valorar las vivencias de la gente de Traful. Todo estos debe estimularnos a redoblar esfuerzos y trabajar mucho más, para que más turistas regresen contentos y con muchas ganas de volver, y que nuestra gente a través del trabajo fecundo y creativo, pueda ir haciendo realidad sus proyectos, sus sueños de manera sostenible. Esta Villa de poco más de 70 años y ubicada en un lugar de privilegio dentro de la Patagonia Argentina, necesita más que nunca del apoyo de nuestro gobierno Provincial, se deben realizar muchas inversiones en infraestructura, para que la comunidad logre su autosustentabilidad trabajando con el turismo. Es un gran desafio y una gran esperanza de nuestro pueblo" (Diciembre de 2007)

Se observa la permanente apelación a la noción de sustentabilidad y protección de la naturaleza, que en este caso implica la necesidad financiamiento provincial, para la realización de obras infraestructurales que permitan un crecimiento local de la oferta de servicios turísticos.

Para el municipio, el turismo sólo podrá desarrollarse en la medida que se generen condiciones infraestructurales básicas que permitan un aprovechamiento sustentable del patrimonio natural. Ahora bien, la definición general de desarrollo sostenible que sostiene la comuna constituye un discurso hegemonizante que invisibiliza las diferentes interpretaciones locales que pueden surgir en vinculación con la premisa de desarrollo. Con relación a esto nos proponemos ejemplificarlo a través de una situación conflictiva que se presentó en la localidad como consecuencia de la licitación para la construcción de un hotel spa.

\section{¿Desarrollo para quién? Freno a la construcción del hotel spa}

La comunidad de Traful y la Cámara de Comercio se organizaron para inhibir la construcción de un hotel spa, presentado y avalado por la provincia en 2006. Los miembros de dichas instituciones movilizaron acciones políticas por considerar que dicho emprendimiento era negativo y una involución en su proceso de desarrollo. Los funcionarios de la Comisión de Fomento a fines de 2008 con referencia a esta situación señalaron que en aquel entonces,

"Se acuerda con la provincia la licitación para dos hosterías con un máximo de 50 plazas. Para quien hace la inversión le cierran los números porque trabaja con un buen número de pasajeros (...) y por otro lado no degrada el ambiente, no causa un impacto negativo tan importante" (Ex funcionario Comisión de Fomento, área turismo)

El gobierno provincial incumplió el acuerdo, según señalan las autoridades de la Comisión de Fomento, y licitó tres hosterías de 50 plazas cada una y un hotel de 200 plazas,

"El hotel tenía nombre y apellido. Mientras que a las hosterías le pusieron tantos requisitos, un pliego súper exigente, por lo tanto no se presentó nadie". (Ex Presidente de la Comisión de Fomento)

Estas instituciones convocaron a los pobladores a movilizarse y frenar la construcción del hotel. La Cámara de Comercio presentó reclamos formales a la provincia y cuando llegaron a la localidad funcionarios provinciales encargados de planificar la construcción del emprendimiento, sorprendieron con una manifestación.

"No es una cuestión de rechazar todo lo que produce el gobierno provincial o el gobierno nacional, no, no es así. Pero espontáneamente cuando las cosas se ve que no son para el pueblo, que no sirven, que no dan un beneficio directo, se pelea por eso..." (Ex integrante de la Comisión de Fomento y de la Cámara de Comercio)

Entre los rumores que circulaban, señalaban que la construcción del hotel estaría emplazado en un campo de invernada de una familia de primeros pobladores. 
“...del otro lado ahi arriba querían hacer un spa, un hotel de 5 pisos y quitarnos el territorio. Nosotros no íbamos a poder tener más animales porque iban a estorbar." (María, familia de primeros pobladores).

En las apariciones públicas de los integrantes de la Cámara de Comercio, se mostraban solidarios con los pobladores de Villa Traful, frente al "rumor" de que iban a restringirles sus territorios. Así el problema o la discusión pública ponía como centro de disputa una posible expropiación, sin visibilizar otro tipo de afectaciones, por ejemplo las comerciales. Consideramos que por el modo en que la Cámara de Comercio hizo público su reclamo, y por cómo nos lo relató la preocupación radicaba en el bienestar de la población en su conjunto, sin visibilizar su interés sectorial vinculado al modo en que se aprovechan y redistribuyen las ganancias provenientes del turismo en la localidad y del control que ejercen sobre el mismo. Durante las gestiones para frenar la construcción, tuvieron reuniones con la provincia, que les explicó a los pobladores la supuesta importancia para la localidad de dicho emprendimiento,

"Vos lo ves asi en una pizarra, en un gabinete y decís 120 puestos de trabajo para una población de 500 y decís realmente estos tipos están locos, nunca lo van a rechazar (...) Pero... ¿De dónde vamos a sacar los 120, las 120 personas capacitadas para que trabajen en el hotel? Es indudable que tenes que traerlas de afuera." (poblador de Villa Traful, ex funcionario de la Comisión de Fomento)

La cantidad de trabajadores que demandaría un espacio de estas características y el supuesto impacto turístico, también constituyó uno de los argumentos contra la construcción del hotel. El planteó se centró en la comparación con la vecina localidad de Villa La Angostura, la cual, como consecuencia de un crecimiento rápido y sin control, actualmente se encuentra con importantes problemas medioambientales y conflictos con relación al acceso de la vivienda de los trabajadores que se asentaron en la localidad ${ }^{15}$.

Otro de los tópicos argüidos para sostener la negativa a la construcción del hotel-spa se vincula con un rumor que se difundió en el pueblo donde el emprendimiento turístico se vinculaba con el "lavado de dinero".

"Es una inversión que no la vas a recuperar nunca porque acá son dos meses de temporada. ¿Quién va a venir y meter esa cantidad de plata para no recuperarla nunca? Alguien que venga a lavar guita" (habitante de Villa Traful, integrante de la Cámara de Comercio).

La rápida dispersión del rumor en el pueblo acerca del origen del dinero, el lugar de la construcción o la negatividad que significaría para el pueblo en términos económicos y socioambientales, consolidó la oposición de los habitantes frente a la construcción del spa.

El rumor sobre la hostería, focalizaba en diferentes cuestiones que involucraban a distintos actores de la localidad, por un lado la expropiación de los terrenos de los pobladores, situación que se hace verosímil dado la historia de desalojos de la región. Por otro lado la acusación del lavado de dinero, y que además la llegada de quienes están realizando esta actividad tienen poder y es esto lo que garantiza que pueda obtener de manera espuria la hostería, que además modificará la vida del pueblo.

Entendemos que el "rumor", constituye un hecho comunicativo basado en un fundamento real, pero que al ser poco claro o distorsionado genera situaciones de tensión y expectativas con un sentido e intencionalidad definidas (Ritter 2000). Es fundamental, el efecto que tuvo el rumor en la localidad, generando una postura definida (la negativa) y un proceso de organización. En este sentido, los dichos tiene el efecto de movilizar y activar el proceso político asociado a las problemáticas del "desarrollo" deseado/impuesto en la localidad. Finalmente, luego de variadas protestas, se logró frenar la construcción de este hotel y flexibilizar los requisitos para la

\footnotetext{
${ }^{15}$ No obstante cabe señalar que la situación estructural de la tierra en ambas localidades es diferente. Las 8.000 hectáreas que componen el ejido de Villa La Angostura en el pasado eran lotes pastoriles vendidos o adjudicados por Tierras y Colonias (cuando Neuquén aún era Territorio Nacional). Cuando se traspasan a la provincia ya existían títulos de propiedad con lo cual estaba abierta la posibilidad de comprar y venderlos. Esto abrió la posibilidad a la especulación y negociados por la tierra, por los cuales aún persisten conflictos y títulos entregados de manera irregular. Esto es diferente en Villa Traful donde actualmente y por el traspaso de parques a provincia, existen 620 hectáreas fiscales y escasos títulos de propiedad.
} 
construcción de las hosterías. En este proceso de movilización, la población denotó una fuerte cohesión comunitaria alrededor del tema.

El rumor, activó una acción política, tanto por parte de la Cámara de Comercio, como por parte de los pobladores, motivado por intereses disímiles pero que confluyeron en un consenso generalizado. La homogeneidad de la población local en el reclamo, fue motivada por una heterogeneidad de intereses a veces superpuestos: mientras que para algunos estaba en juego la posible pérdida de sus territorios, se oponían por "el impacto negativo para el medioambiente". Lo que quedó en claro y el resultado de este rumor fue que a nadie le parecía conveniente la instalación de la hostería. Así estos rumores y el proceso de movilización fue motivado por intereses diversos en función de los intereses sectoriales.

El presidente de la Cámara de Comercio y su principal asesor, ambos pertenecientes a la Comisión de Fomento, sostuvieron que el "pueblo" se opuso porque el interés del colectivo es impulsar en la localidad un desarrollo controlado y sustentable. Ahora bien estas aparecen como premisas consensuadas desde lo local, pero en este caso que implicó movilización y conflictividad social nos permitió reconocer intereses diferenciales en relación a la apropiación, uso y control de los recursos naturales.

\section{Conclusiones}

En Villa Traful la naturaleza es catalogada como un bien a ser preservado por su inmanente belleza natural. Esto nos permite observar de qué manera la categoría de territorio y las retóricas del paisaje y significación de la naturaleza permiten identificar el modo en que las políticas del Estado configuraron una visión hegemónica del mismo. En esta localidad, la naturaleza se presenta como espacio significativo a través de la estetización discursiva y las políticas de preservación.

Cabría preguntarse, ¿Es la estética lo que define el proceso de preservación? ¿Cuáles son las dinámicas sociales y de poder que configuran a la naturaleza como espacio de preservación? Consideramos fundamental señalar que la naturaleza está inserta en la historia y por lo tanto sometida al cambio y la variación. Asimismo esta historicidad de la naturaleza no puede estar escindida de los modos en que Occidente fue imponiendo diseños espaciales sobre el globo al organizar y dar sentido al espacio natural y social de acuerdo con principios económicos, culturales y epistemológicos que declaró universales. En ese sentido, en el marco de las actividades productivas y las relaciones sociales y políticas, la naturaleza es apropiada bajo estos patrones estéticos y conservacionistas. En la actualidad, son estos patrones los que delimitan la mercantilización de la misma a través de la actividad turística. Esto da lugar a conflictos por la apropiación y uso del patrimonio "natural".

En este marco y bajo estas condiciones del paisaje se dirimen procesos vinculados al "desarrollo sustentable" de la villa y su entorno. Las autoridades políticas - $\mathrm{PNNH}$, el gobierno provincial y el municipio- esgrimen argumentos que buscan combinar sustentabilidad y desarrollo económico vinculado a la gestión y uso de los recursos naturales. Actualmente se encuentra en etapa de implementación de políticas vinculadas al turismo, tales como el "Plan Federal de Turismo" del Estado nacional, como el "Plan de Turismo" implementado por el gobierno provincial. El grado de éxito o fracaso del mismo dependerá de muchos factores, sin embargo, consideramos central el reconocimiento de la trama conflictiva que revista la experiencia de los pobladores de Villa Traful. En este sentido, en el artículo quisimos poner en relieve el entretejido de intereses, alianzas y enemistades que se encuentra ligado a una experiencia histórica marcada por la clasificación de los sujetos en función de la forma en que los mismos se vinculan en su entorno natural así como las tramas de poder que definen y acotan los modos en que la experiencia social tiene lugar. En este sentido, recuperamos la perspectiva de Escobar (1996) respecto de la necesidad de "desnaturalizar" los proyectos y propuestas vinculados al 
"desarrollo endógeno", para concentrarnos en los procesos históricos internos a los territorios y su relación con las políticas públicas generadas a partir de la agencialidad estatal.

\section{Bibliografía}

ALMIRÓN, A; R. BERTONCELLO; C. TRONCOSO. (2006). "Turismo, patrimonio y territorio: una discusión de sus relaciones a partir de casos de Argentina". Estudios y perspectivas en turismo. Vol. 15.2- Argentina (pags 101-124).

BENEDETTI, Cecilia; CARENZO, Sebastián. (2006). "Territorio e identidades: Reflexiones en torno a la construcción de nuevos paradigmas en el desarrollo". Trabajo de seminario doctoral: ¿Desarrollo rural, desarrollo local-rural, desarrollo territorial rural? (en busca de un paradigma para América Latina). Buenos Aires: Mimeo.

BERSTEN, Lara. (2009). "Consolidación del Estado argentino en norpatagonia. El caso de Villa Traful, provincia de Neuquén”. Claroscuro No 7- Rosario, Argentina (págs 79-103).

BERTONCELlO, R. (2000). Turismo en los Andes Patagónicos. Valorización turística de áreas de preservación ambiental. Actas Latinoamericanas de Varsovia. Universidad de Varsovia, Varsovia (págs 43-58).

CARPINETTI, B. (2005). Derechos indígenas en el Parque Nacional Lanin. Administración de Parques Nacionales, Buenos Aires.

COLMEGNA, P. Y C. MATARAZZO. (2001). "Una perspectiva antropológica sobre el desarrollo". Revista Theomai $\mathrm{N}^{\mathrm{o}} 3$ 0-0. Disponible en: http://www.unq.edu.ar/revista-theomai.

DE MENDIETA, Y. (2002). Una Aldea de Montaña. Villa La Angostura y su historia en la Patagonia. Bavaria, San Carlos de Bariloche.

ESCOBAR, A. (1996). La invención del desarrollo. Norma, Bogotá.

ESCOBAR, A. (2005). "El postdesarrollo como concepto y como práctica social"- en Politicas de economía, ambiente y sociedad en tiemos de globalización- Mato, D. (COORD.). Facultad de Ciencias Económicas y Sociales, Universidad Central de Venezuela, Caracas.

ESTEVA, Gustavo. (2000). "Desarrollo"- Antropología del desarrollo. Teorías y estudios etnográficos en América Latina- Viola, A (COMP.). Paidós, Barcelona.

FERNANDES, B. (2010). “Acerca de la tipología de territorios". Defensa comunitaria del territorio en la zona central de México. Enfoques teóricos y análisis de experiencias- Rodriguez Wallenius, C. (COORD). Juan Pablo editores, Xochimilco.

FORTUNATO, N. (2005). "El territorio y sus representaciones como fuente de recursos turísticos”. Estudios y perspectivas en turismo Vol. 4.14- Argentina (págs 314-348).

GARCÍA CANCLINI, N. (1993). "Los usos sociales del patrimonio cultural”- en El patrimonio cultural de México- Florescano, E. (COMP). Fondo de Cultura Económica, México.

GARCÍA, A. Y L. BERSTEN Y F. TRENTINI. (2008). "Villa Traful: un pueblo patagónico de frontera". Relatos Patagónicos. Historias familiares en la construcción del espacio social en Villa Traful- en Valverde, S; García, A y Bersten, L. Ferreyra editor, Córdoba. 
GLACKEN, C. (1996). Huellas en la playa de Rodas. Naturaleza y cultura en el pensamiento occidental desde la Antigüedad hasta finales del siglo XVIII. Ediciones Serbal, Barcelona.

GUDYNAS, E. (2010). "Desarrollo sostenible: guía básica de conceptos y tendencias hacia otra economía". Otra Economía- Revista Latinoamericana de economía social y solidaria. Vol. 4. $\mathrm{N}^{\mathrm{o}}$ 6- Buenos Aires, Argentina (págs 43-66).

GUIMARÃES, R. (1994). "El desarrollo sustentable ¿propuesta alternativa o retórica neoliberal?" Eure Vol. XX. No 61- Santiago de Chile, Chile (págs 41-56).

MANNHEIM, Karl. (1984). El hombre y la sociedad en época de crisis. Leviatán, Buenos Aires.

MANZANAL, Mabel. (2005). Regiones, territorios e institucionalidad en el desarrollo rural. Buenos Aires: Mimeo.

MANZANAL, Mabel. (2007). "Territorio, poder e instituciones. Una perspectiva crítica sobre la producción del territorio"- en Territorios en construcción. Actores, tramas y gobiernos: entre la cooperación y el conflicto- Manzanal, M; Arzeno, M y Nussbaumer, B (COMPS). Ciccus, Buenos Aires.

MASTRANGELO, A. (2009). "Análisis del concepto de recursos naturales en dos estudios de caso de Argentina". Ambiente \& Sociedade Vol. 12 № 2- San Pablo, Brasil (págs 341-355).

MÉNDEZ, Laura. (2009). "El estigma del origen. Chilenos e indígenas en el gran lago 18801935"- en Historias de las familias mapuche Lof Paichil Antriao y Lof Quintriqueo de la margen norte del lago Nahuel Huapi G. Ghioldi, G (COMP). Archivos del Sur. Villa La Angostura.

NAVARRO FLORIA, Pedro. (2008). "La "Suiza argentina", de utopía agraria a postal turística: la resignificación de un espacio entre los siglos XIX y XXI". Jornadas de Historia de la Patagonia. Bariloche: CD.

NUÑEZ, P. Y L. VEJSBERG. (2010). "El turismo, entre la actividad económica y el derecho social. El parque Nacional Nahuel Huapi, Argentina, 1934-1955". Estudios y Perspectivas en Turismo. Vol. 19, Buenos Aires, Argentina (págs 930-945).

PÉREZ, Alejandra. (2009). "Parque Nacional Nahuel Huapi. ¿Un instrumento de progreso o una política de exclusión?"- en El territorio en perspectiva. Política pública y memoria social en Villa Traful- García, A y Bersten, L. (EDS). Buenos Aires, Secretaría de Políticas Universitarias.

REBORATTI, C. (1999). Ambiente y Sociedad: conceptos y relaciones. Ariel, Buenos Aires. Ritter, Michael. (2000). "El rumor un análisis epistemológico". Disponible en Disponible en: http://ritterandpartners.median-webstudio.de/es/documentos/documentos.html

SCARZANELLA, E. (2002). Las bellezas naturales y la nación: los parques nacionales en Argentina en la primera mitad del siglo XX. Revista Europea de Estudios Latinoamericanos y del Caribe. № 73, Amsterdam (págs 5-21). 